\title{
SINTESIS Y-AL $2 \mathrm{O}_{3}$ DARI ZEOLIT ALAM SUMBAWA
}

\section{SYNTHESIS OF $\mathrm{V}-\mathrm{AL}_{2} \mathrm{O}_{3}$ FROM SUMBAWA NATURAL ZEOLITE}

\author{
Emsal Yanuar, ${ }^{1, *}$, Zulkifli $^{1}$, Wirya Sarwana ${ }^{1}$, Eka Putra Ramdhani ${ }^{2}$ \\ ${ }^{1}$ Universitas Teknologi Sumbawa \\ Jalan Raya Olat Maras, Kecamatan Moyo Hulu, Kabupaten Sumbawa, 84371 \\ ${ }^{2}$ Universitas Maritim Raja Ali Haji \\ Jalan Politeknik Senggarang, Tanjungpinang Kepulauan Riau, 29115 \\ *e-mail korespondensi: emsal.yanuar491@uts.ac.id
}

\begin{abstract}
Abstrak
$\mathrm{\gamma}-\mathrm{Al}_{2} \mathrm{O}_{3}$ merupakan material yang paling luas digunakan sebagai substrat katalis dalam otomotif dan industri petroleum, komposit struktural untuk pesawat luar angkasa, serta pelapis tahan panas (Thermal wear coatings). Kandungan aluminium dari zeolite alam sangat potensial dalam sintesis $\gamma$ $\mathrm{Al}_{2} \mathrm{O}_{3}$, sehingga pada penelitian ini difokuskan pada pemisahan alumina dengan besi dan silika menggunakan metode pelindihan dilanjutkan dengan presipitasi, sebagai bahan dasar sintesis $\gamma-\mathrm{Al}_{2} \mathrm{O}_{3}$ dengan memvariasikan suhu kalsinasi. Berdasarkan hasil analisis yang dilakukan pemisahan alumina dengan besi dan silika dari zeolite alam Sumbawa berhasil dilakukan. Hal ini ditunjukan dengan persentase alumina sebesar $89.80 \%$, sehingga sangat potensial sebagai bahan dasar sintesis $\gamma-\mathrm{Al}_{2} \mathrm{O}_{3}$. Selain itu, dari ketiga variasi suhu kalsinasi yaitu pada 550,650 , dan $750{ }^{\circ} \mathrm{C}$ dalam penelitian ini, suhu $750{ }^{\circ} \mathrm{C}$ merupakan suhu yang baik dalam pembentukkan y $-\mathrm{Al}_{2} \mathrm{O}_{3}$.
\end{abstract}

Kata kunci: pemisahan aluminium, pelindihan, proses presipitasi, kalsinasi, $\mathrm{\gamma}-\mathrm{Al}_{2} \mathrm{O}_{3}$

\begin{abstract}
In this study, Synthesis of $\gamma-\mathrm{Al}_{2} \mathrm{O}_{3}$ (Gamma Alumina) from Sumbawa natural zeolite using precipitation method was investigated. Natural zeolite was leached with the hydrochloric acid followed by precipitation process the leached solution by controlling the $\mathrm{pH}$ to obtain the aluminum hydroxide. The $\gamma-\mathrm{Al}_{2} \mathrm{O}_{3}$ were synthesized from aluminum hydroxide by calcination process at different temperatures $\left(550^{\circ} \mathrm{C}, 650^{\circ} \mathrm{C}\right.$ and $\left.750^{\circ} \mathrm{C}\right)$, respectively. The synthesized products have been characterized by meant of X-ray diffraction (XRD), X-ray fluorescence (XRF), Scanning Electron Microscopy (SEM) and FTIR (Fourier Transform Infra Red) spectroscopy. Besides that, in this research mechanism of reaction was also discussed. The experiment results showed that gamma alumina has been successfully synthesized. Based on XRD pattern, at temperatures of $550^{\circ} \mathrm{C}, 650^{\circ} \mathrm{C}$ and $750^{\circ} \mathrm{C}$ have shown peaks of the $\gamma-\mathrm{Al}_{2} \mathrm{O}_{3}$. The increasing temperature of calcination indicates the increasing of gamma alumina crsytallinity. XRF analysis result, the composition of $\mathrm{Al}$ increased from $21 \%$ to $89 \%$ after the precipitation process. Whereas, FTIR spectroscopy test results have also confirmed the formation of gamma alumina.
\end{abstract}

Keywords: natural zeolite, leaching, precipitation process, calcination, gamma-alumina.

\section{PENDAHULUAN}

Aluminium oksida atau alumina dengan rumus kimia $\mathrm{Al}_{2} \mathrm{O}_{3}$ digunakan sangat luas di bidang teknologi dan industri sebagai Katalis, adsorben, biomaterial, komposit, dan logam ringan (P.Tartaj et al, 2002). Alumina memiliki beberapa struktur seperti fasa $\alpha-, \gamma^{-}, \eta_{-}^{-}, \delta-, \theta-, \kappa-$ , dan $\chi_{-}$, (Digne et al, 2002: Wang et al, 2008). Masing - masing fasa tersebut mempunyai sifat fisis yang berbeda dan diantara struktur transisi tersebut fasa $\mathrm{\gamma}-\mathrm{Al}_{2} \mathrm{O}_{3}$ merupakan material yang paling luas digunakan sebagai substrat katalis 
dalam otomotif dan industri petroleum, komposit struktural untuk pesawat luar angkasa, serta pelapis tahan panas (Thermal wear coatings) (Wang et al, 2008). Hal ini disebabkan karena $\gamma-\mathrm{Al}_{2} \mathrm{O}_{3}$ memiliki struktur kubik yang higroskopis dan larut dalam asam, sedangkan $\alpha$ $\mathrm{Al}_{2} \mathrm{O}_{3}$ memiliki struktur oktahedral seperti corundum/sapphire yang sangat keras karena memiliki sifat kesetabilan yang sangat tinggi sehingga tidak mudah larut dalam asam (Partington, 1961).

Sintesis alumina telah banyak dilaporkan dari berbagai material seperti bauksit, kaolin, abu batu bara (Yan et al, 2016) dan zeolite. Zeolite adalah kelompok mineral yang kandungan utamanya adalah silika dan alumina, sehingga memiliki potensi untuk dijadikan sebagai bahan dasar sintesis alumina. Disis lain, metode untuk sintesis alumina umumnya menggunakan metode basa atau lebih dikenal dengan proses Bayer. Metode basa atau proses Bayer telah digunakan untuk memisahkan alumininium dari bijih Nepheline dan bauksit dengan menkontrol suhu pelindihan. Namun dalam proses Bayer ini terdapat batasan dimana jumlah kandungan silika dari minerial tidak boleh melebihi 10\% (Andreas, 2012). Lain dengan proses bayer, metode asam yang dilanjutkan dengan proses presipitasi dapat memisahkan silika ataupun pengotor lainnya dengan alumina meskipun kandungan silika melebihi $10 \%$, seperti pada zeolite alam yang memiliki kadar silika diatas 50\%. Mineral zeolite alam dalam peneltian ini berasal dari pulau Sumbawa.

Sebagai daerah yang terkenal dengan kekayaan mineral, Sumbawa memiliki mineral zeolite alam yang telah ditetapkan sebagai sumber aluminium selain bauksit. Kandungan silika dari zeolite alam yang tinggi sekitar $54.6 \%$ dan $21.1 \%$ alumina, dapat disintesis dengan metode pelindihan dilanjutkan dengan presipitasi. Metode ini dapat dilakukan dalam sekala laboratorium, tidak membutuhkan peralatan yang rumit dan ekonomis.

Sehingga pada penelitian ini dilakukan pemisahan aluminium dari zeolite alam yang memanfaatkan sumber potensi lokal Sumbawa dengan metode asam dan proses presipitasi sebagai bahan dasar sintesis $\mathrm{\gamma}-\mathrm{Al}_{2} \mathrm{O}_{3}$.

\section{METODE PENELITIAN}

Zeolite alam yang masih berupa bongkahan/batuan sedimen pada tahap awal digerus secara manual menggunakan mortar dan alu dengan tujuan agar mendapatkan ukuran yang lebih kecil. 100 gram zeolite alam dilakukan proses pelindihan asam menggunakan asam klorida pada suhu $90^{\circ} \mathrm{C}$ selama 2 jam. Larutan hasil leaching ditambahkan $6 \mathrm{M} \mathrm{NaOH}$ hingga $\mathrm{pH}$ basa untuk memisahkan pengotor seperti besi. Selanjutnya larutan akan dikondisikan $\mathrm{pH}$ netral untuk mendapatkan endapan $\mathrm{Al}(\mathrm{OH})_{3}$. Kemudian disaring, dicuci dan dikeringkan. Sampel yang telah dikeringkan dikalsinasi pada suhu 550, 650 dan $750{ }^{\circ} \mathrm{C}$ selama 4 jam. Zeolite alam, alumina yang telah disintesis dan alumina yang telah dikalsinasi selanjutnya dikarakterisasi menggunakan XRD, XRF, FTIR, dan SEM untuk mengetahui kristalografi, gugus fungsi dan morfologi setelah disintesis.

\section{HASIL DAN PEMBAHASAN}

Pada penelitian ini dilakukan pemisahan aluminium oksida dengan silika dan besi dari mineral zeolite alam. Mineral zeolite alam dengan jenis Gismondin secara umum memiliki puncak pada $2 \theta: 21^{\circ}, 30^{\circ}, 26^{\circ}$, dan $50^{\circ}$, hal ini ditunjukan dengan Gambar 1. analisis XRD mineral zeolite alam yang digunakan pada penelitian ini dengan gismondin memiliki puncak yang sama, sehingga zeolite alam dalam penelitian ini merupakan jenis gismondin. Komposisi silika yang tinggi pada penelitian ini ditunjukkan oleh puncak difraksi silika yang dominan pada posisi $20.8404^{\circ}, 26.63274^{\circ}$, $50.11207^{\circ}$, sehingga silikon oksida merupakan komposisi utama dari mineral zeolite alam yang digunakan dalam penelitian ini.

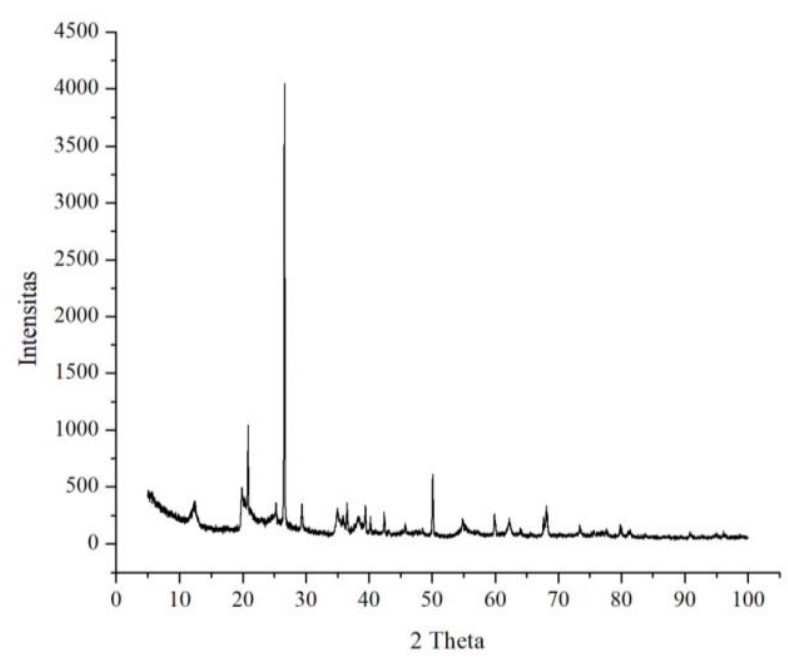

Gambar 1. Pola XRD dari mineral Zeolit alam yang digunakan dalam penelitian ini. 
Untuk mengetahui persentasi alumina yang dihasilkan dilakukan analisis XRF yang ditunjukan oleh Tabel 2. menunjukan komposisi kimia sebelum dan setelah disintesis. Komposisi aluminium oksida yang mencapai $89.80 \%$ adalah persentase komposisi yang tinggi dibandingkan dengan logam oksida lainnya. Peningkatan persentase alumina dalam penelitian ini disebabkan karena pengotor seperti silika yang tidak larut bersamaan pada proses leaching dan besi sudah terpisah menjadi endapan pada proses pengkontrolan $\mathrm{pH}$. Hal ini juga dapat dilihat dari gambar SEM pada kedua sampel sebelum dan setelah disintesis yang ditunjukan pada Gambar 4.7 yang menggambarkan adanya perbedaan ukuran partikel dan warna. Sehingga silikon, besi dan logam lainnya berhasil dipisahkan dalam proses sintesis. Lain dengan kalsium oksida yang persentase komposisinya semakin meningkat, hal ini dikarenakan pada proses leaching kalsium oksida larut bersamaan dengan aluminium oksida dan mengalami pengendapan bersamaan dengan aluminium oksida.

Tabel 1. Komposisi Kimia dari sebelum disintesis dan setelah disintesis pada penelitian ini

\begin{tabular}{|c|c|c|c|c|c|c|c|}
\hline Element & Al & $\mathbf{S i}$ & $\mathrm{Fe}$ & $\mathbf{C a}$ & Mn & $\mathrm{Cu}$ & $\begin{array}{c}\text { Logam } \\
\text { Lainny } \\
\text { a }\end{array}$ \\
\hline $\begin{array}{c}\text { Komposis } \\
\text { i sebelum } \\
\text { disintesis } \\
(\%)\end{array}$ & $\begin{array}{c}21.1 \\
0\end{array}$ & 54.60 & 10.50 & 1.20 & 0.18 & 0.15 & 12.27 \\
\hline $\begin{array}{c}\text { Komposis } \\
\text { i setelah } \\
\text { disintesis } \\
(\%)\end{array}$ & $\begin{array}{c}89.8 \\
0\end{array}$ & 0.12 & 0.19 & 4.08 & 0.08 & 0.13 & 5.60 \\
\hline
\end{tabular}

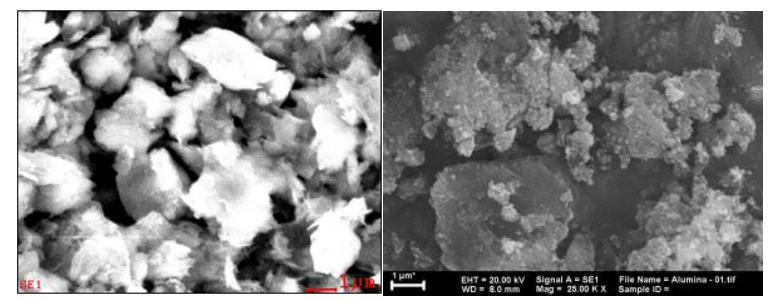

Gambar 2. SEM dari sebelum dan setelah disintesis dalam penelitian ini

Pada penelitian ini untuk mengidentifikasi transformasi fasa aluminium oksida sebelum dan selama proses kalsinasi ditunjukan pada gambar 4.9. Dari pola XRD yang terbentuk memiliki kesesuaian dengan penelitian yang dilakukan oleh Zhu, 2015, bahwa terdapat fasa Kristal $\mathrm{AlOOH}$ yang terbentuk ketika proses presipitasi. Setelah kalsinasi pada suhu $550{ }^{\circ} \mathrm{C} \mathrm{AlOOH}$ akan bertransformasi dalam bentuk $\mathrm{\gamma}-\mathrm{Al}_{2} \mathrm{O}_{3}$.

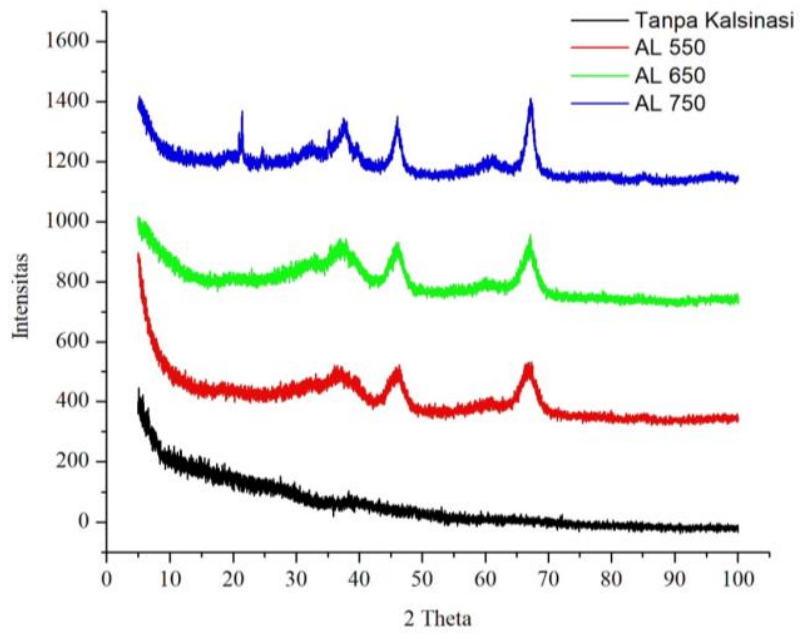

Gambar 3. XRD Pattern $\mathrm{Al}_{2} \mathrm{O}_{3}$ (tanpa Kalsinasi), $\mathrm{Al}_{2} \mathrm{O}_{3} 550$ (Kalsinasi suhu $550{ }^{\circ} \mathrm{C}$ ), $\mathrm{Al}_{2} \mathrm{O}_{3} 650$ (Kalsinasi suhu $650{ }^{\circ} \mathrm{C}$ ), dan $\mathrm{Al}_{2} \mathrm{O}_{3} 750$ (Kalsinasi suhu $750{ }^{\circ} \mathrm{C}$ )

Berdasarkan analisis XRD diperoleh 4 puncak intensitas tertinggi dengan suhu kalsinasi $750{ }^{\circ} \mathrm{C}$ pada $2 \theta: 21.38,37.98,45.97$, dan 67.23 merupakan puncak dari $\gamma-\mathrm{Al}_{2} \mathrm{O}_{3}$. Suhu kalsinasi yang meningkat dari 550, 650 ke $750{ }^{\circ} \mathrm{C}$ membuat fasa $\mathrm{\gamma}-\mathrm{Al}_{2} \mathrm{O}_{3}$ terbentuk dengan jelas, hal ini menyimpulkan peningkatan puncak tertinggi terjadi pada suhu kalsinasi $750{ }^{\circ} \mathrm{C}$. disisi lain, untuk mengetahui gugus fungsi alumina yang terbentuk pada difraksi XRD dilakukan analisis FTIR.

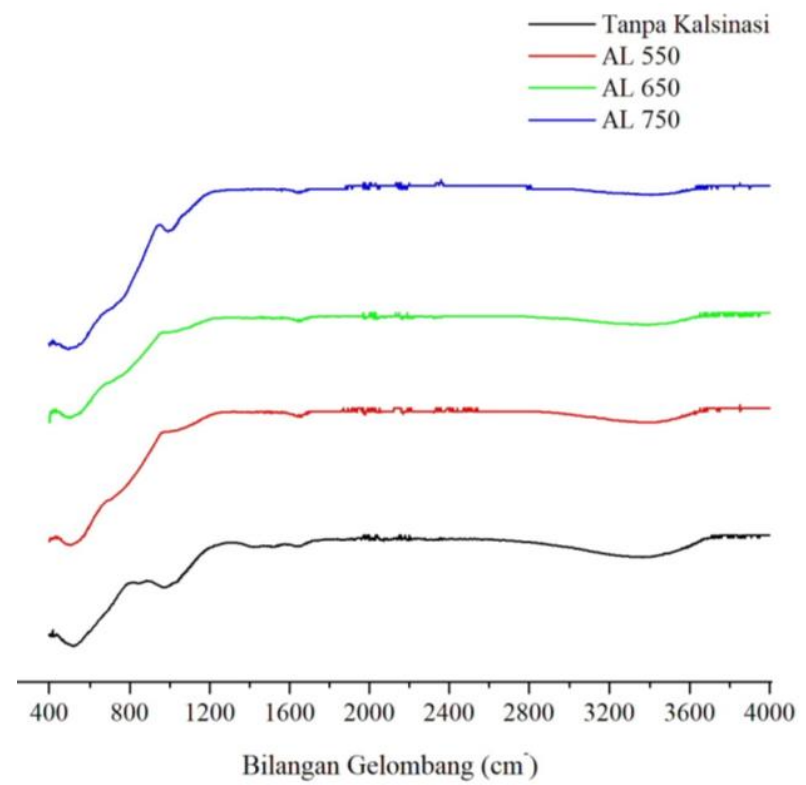

Gambar 4. Spektrum $\mathrm{Al}_{2} \mathrm{O}_{3} 550$ (Kalsinasi suhu $550{ }^{\circ} \mathrm{C}$ ), $\mathrm{Al}_{2} \mathrm{O}_{3} 650$ (Kalsinasi suhu $650{ }^{\circ} \mathrm{C}$ ), dan $\mathrm{Al}_{2} \mathrm{O}_{3} 750$ (Kalsinasi suhu $750{ }^{\circ} \mathrm{C}$ ). 
Analisis FTIR sebelum dan setelah disintesis ditunjukan pada gambar 5.0 menggambarkan ilustrasi spektra IR dari ke lima sampel. Pada spektra IR zeolite alam menunjukan adanya vibrasi ikatan $\mathrm{O}-\mathrm{Si}-\mathrm{O}$ dan $-\mathrm{O}-\mathrm{Al}-$ O. Vibrasi ikatan yang lainnya terjadi pada 3408.84 dan $1637.99 \mathrm{~cm}^{-1}$ yang menjelaskan adanya vibrasi ulur dan tekuk dari ikatan $\mathrm{OH}$. Namun seiring dengan peningkatan suhu kalsinasi ikatan $\mathrm{OH}$ semakin tidak terlihat, hal ini disebabkan karena suhu kalsinasi yang digunakan dalam penelitian ini mampu menghilangkan senyawa organik termasuk $\mathrm{OH}$. Lain dengan $\mathrm{OH}$, vibrasi ikatan $\mathrm{O}-\mathrm{Si}-\mathrm{O}$ tidak terlihat pada spektra IR Al (tanpa Kalsinasi), AL550 (Kalsinasi suhu $550{ }^{\circ} \mathrm{C}$ ), AL650 (Kalsinasi suhu $650{ }^{\circ} \mathrm{C}$ ), dan AL750 (Kalsinasi suhu $750^{\circ} \mathrm{C}$ ), hal ini disebakan oleh silika yang sudah berhasil dipisahkan pada saat proses sintesis. Sedangkan, vibrasi lainnya pada spektra IR Al (tanpa Kalsinasi), AL550 (Kalsinasi suhu $550{ }^{\circ} \mathrm{C}$ ), AL650 (Kalsinasi suhu $650{ }^{\circ} \mathrm{C}$ ), dan AL750 (Kalsinasi suhu $750{ }^{\circ} \mathrm{C}$ ) terjadi persebaran pita yang paling kuat dari $300-1000 \mathrm{~cm}^{-1}$ untuk - $\mathrm{Al}-\mathrm{OH}$ dan $-\mathrm{O}-\mathrm{Al}-\mathrm{O}-\mathrm{Al}$ - yang sesuai dengan karakterisitik vibrasi dari $\mathrm{Al}_{2} \mathrm{O}_{3}$.

\section{KESIMPULAN}

Berdasarkan hasil penelitian didapatkan kesimpulan bahwa pemisahan alumina dengan besi dan silika menggunakan metode presipitasi dari zeolite alam Sumbawa berhasil dilakukan. Hal ini ditunjukan dengan persentase alumina sebesar $89.80 \%$, sehingga sangat potensial sebagai bahan dasar sintesis $\mathrm{\gamma}^{-}-\mathrm{Al}_{2} \mathrm{O}_{3}$.
Berdasarkan analisis XRD dari ketiga variasi suhu kalsinasi dalam penelitian ini, suhu $750{ }^{\circ} \mathrm{C}$ merupakan suhu yang baik dalam pembentukkan $\mathrm{\gamma}-\mathrm{Al}_{2} \mathrm{O}_{3}$.

\section{DAFTAR RUJUKAN}

Andreas, A.W, 2012, Pengaruh temperatur pada proses Bayer terhadap ekstraksi alumina pada bijih Nepehline, FT UI.

Belver, C., Munoz, M.A.B., Vicente, M.A., 2002. Chemical activation of a kaolinite under acid and alkaline conditions. Chem. Mater.14.2033-2043.

Digne, M., Sautet, P., Raybaud, P., Toulhoat, H., Artacho, E., 2002, Structure and Stability of Aluminium Hydroxides: a theoritical study.J. Catal. 166, 340 - 346.

Parida, K.M., Pradhan, A.C., Das, J., Sahu, N., 2009. Synthesis and characterization of nano - sized porous gamma - alumina by control precipitation method. Mater. Chem. Phys. 113,244 -248.

Shabaker, A.H., Pa, M., 1949. Process of acidactivating kaolin clay. US patent 2477664.

Ting yan, Xiaode Guo, Xiang Zhang, Zhixiang Wang, Jinqiu Shi, 2016, Low temperature synthesis of nano alpha-alumina powder by two-step hydrolysis, Materials Research Bulletin, 73, 21-28

Zhou, S.X., Antoneitti, M., Niederberger, M., 2007. Low temperature to synthesis of $y$ $\mathrm{Al}_{2} \mathrm{O}_{3}$ nanocrystals from aluminum acetylacetonate in nonaqueous media. Small 3, $763-767$. 